\title{
Preparation of thermo-responsive acrylic hydrogels useful for the application in transdermal drug delivery systems
}

\author{
Trong-Ming Don ${ }^{\text {a }}$, Mei-Lien Huang ${ }^{b}$, Ai-Chien Chiu ${ }^{c}$, Kuo-Huai Kuo ${ }^{b}$, \\ Wen-Yen Chiu ${ }^{b, d, *}$, Lien-Hua Chiu ${ }^{e}$ \\ ${ }^{a}$ Department of Chemical and Materials Engineering, Tamkang University, Tamsui, Taipei County 25147, Taiwan \\ ${ }^{\mathrm{b}}$ Department of Chemical Engineering, National Taiwan University, Taipei 106, Taiwan \\ ${ }^{\mathrm{c}}$ Department of Physics, National Taiwan University, Taipei 106, Taiwan \\ ${ }^{\mathrm{d}}$ Institute of Polymer Science and Engineering, National Taiwan University, Taipei 106, Taiwan \\ e Taiwan Textile Research Institute, Tucheng, Taipei County 236, Taiwan \\ Received 6 January 2007; received in revised form 15 June 2007; accepted 14 July 2007
}

\begin{abstract}
In this research, hydrogel membranes mainly composed of three kinds of latex particles within carboxymethyl cellulose (CMC) matrix were prepared for the purpose of transdermal drug release. All three latex particles were acrylic systems and synthesized by emulsion polymerization with the addition of an initiator, potassium persulfate, and a crosslinking agent, methylene bisacrylamide. Among them, poly(acrylic acid-cosodium acrylate) copolymer was applied to increase the swelling ability of hydrogel membrane. Degree of neutralization or the amount of added crosslinking agent was changed to give the optimum properties endowed to the membrane. Poly(acrylic acid-co-2-ethylhexyl acrylate) copolymer latex was used to provide the adhesive ability for the membrane. Finally, to give a thermo-responsive behavior in swelling, poly $(N$-isopropyl acrylamide) latex and its copolymers were synthesized by polymerization of $N$-isopropyl acrylamide with different amounts of acrylic acid, in which lower critical solution temperature (LCST) could be modulated. Besides blending these microgel particles with CMC and several other compounds such as tartaric acid and PAA oligomer used to adjust $\mathrm{pH}$ value of doping solution, aluminum ion ( $\mathrm{Al}^{3+}$ ) was applied to give ionic interaction with carboxylate groups distributed in all three latex particles, thus giving interconnected interactions among all microgel particles and in turn a good membrane formability. Morphology, structures and swelling capability of prepared hydrogel membranes were then examined. Caffeine, used as the model drug, was incorporated into membranes and the drug release behavior at different temperatures was evaluated. These prepared hydrogel membranes have potential in the application of transdermal drug delivery system.
\end{abstract}

(C) 2007 Elsevier B.V. All rights reserved.

Keywords: Hydrogel; Poly( $N$-isopropyl acrylamide); Poly(acrylic acid-co-sodium acrylate); Poly(acrylic acid-co-2-ethylhexyl acrylate); Transdermal drug delivery systems

\section{Introduction}

Hydrogel is a three-dimensional, crosslinked polymer that can retain water at least $20 \%$ of its own weight. It can swell greatly by absorbing water and shrink after de-swelling. The swelling capability depends on the nature of polymer and its crosslinking density. For more than two decades, considerable attention has been drawn to the environmental sensitive hydro-

\footnotetext{
* Corresponding author at: Department of Chemical Engineering, National Taiwan University, Taipei 106, Taiwan. Tel.: +8862 23623259; fax: +886223623259 .

E-mail address: ycchiu@ntu.edu.tw (W.-Y. Chiu).
}

gels or so-called smart hydrogels. These hydrogels can undergo a reversible and yet discontinuous volume change in response to environmental stimuli such as $\mathrm{pH}$ [1], temperature [2-5], ionic strength [6], electric field [7], and so on. These smart gels have potential applications in biomedical and pharmaceutical fields. One of the most well known thermal-responsive polymers is poly ( $N$-isopropylacrylamide) (PNIPAAm), which exhibits a lower critical solution temperature (LCST) at around $32{ }^{\circ} \mathrm{C}$ in an aqueous solution [8]. PNIPAAm hydrogels with crosslinked structure thus can swell in water below the LCST and shrink above it $[9,10]$. In this study, a crosslinked PNIPAAm copolymer was synthesized from NIPAAm with acrylic acid monomer to be incorporated into a hydrogel membrane. The addition of acrylic acid not only provides the ionic interaction with two other latex 
particles via aluminum ion but also gives a shift in LCST toward a higher temperature. Two other latex particles were poly(acrylic acid-co-sodium acrylate) and poly(acrylic acid-co-2-ethylhexyl acrylate) copolymers which were used to increase the swelling and adhesive ability of hydrogel membrane, respectively. Structures and morphologies of latex particles as well as hydrogel membranes were examined. Swelling capability and adhesion property of hydrogel membranes were measured. A model drug using caffeine was loaded into the hydrogel membrane. In this way, we could integrate drug, rate-controlling gel and adhesive matrix into one membrane, in contrast to the traditional sticking plaster. The drug release behavior of the prepared hydrogel membrane at different temperatures was evaluated.

\section{Experimental}

\subsection{Materials}

Acrylic acid (AA), 2-ethylhexyl acrylate (EHA) and $N$-isopropyl acrylamide (NIPAAm), used as monomers, potassium persulfate (KPS) as a free radical initiator, $N, N^{\prime}$-methylene bisacrylamide (MBA) as a crosslinking agent, and sodium dodecyl sulfate (SDS) as a surfactant were all obtained from ACROS (NJ, USA). These compounds were used for the synthesis of copolymer microgels. Poly(acrylic acid) oligomer with a molecular weight of 2000 was supplied by Aldrich. Sodium carboxymethyl cellulose (CMC) with a molecular weight of 25,000, L-(+)-tartaric acid, glycerin and aluminum hydroxide were also purchased from ACROS. They were used to be blended with the synthesized copolymers microgels as ingredients in the final hydrogel membranes. Caffeine (ACROS) was used for the study of drug release. All other chemicals were analytical-grade or above and used as received without further purification.

\subsection{Synthesis of copolymer microgels}

Acrylic acid monomer $(10 \mathrm{~g})$ was added into a $100 \mathrm{ml}$ water containing $0.5 \mathrm{~g}$ of SDS surfactant at $70^{\circ} \mathrm{C}$. The solution was stirred at a speed of $300 \mathrm{rpm}$ and purged with nitrogen. Different amounts of $\mathrm{NaOH}\left([\mathrm{NaOH}]_{0} /[\mathrm{AA}]_{\mathrm{o}}=0.0,0.20\right.$, $0.50,0.80)$ and MBA crosslinking agent $(0.01$ and $0.02 \mathrm{~g})$ were added to the solution. After $10 \mathrm{~min}$ of stirring, KPS initiator $(0.1 \mathrm{~g})$ was added to initiate polymerization. After $3 \mathrm{~h}$ of reaction, crosslinked poly(acrylic acid-co-sodium acrylate) copolymers, poly(AA-co-SA), with different neutralization ratios were obtained. The solution was filtered and dried at $50^{\circ} \mathrm{C}$ in a circulation oven and then in a vacuum oven. After drying, the sample was ground into powder. Different samples are denoted as AS- $X-Y \%$, where $X$ stands for the degree of neutralization $(0.0,0.2,0.5,0.8)$ and $Y \%$ represents the weight percentage of crosslinking agent relative to the added AA monomer (0.1 and $0.2 \%)$. To synthesize poly(acrylic acid-co-2-ethylhexyl acrylate) microgel, poly(AA-coEHA), as an adhesive component, equal amounts of acrylic acid and 2-ethylhexyl acrylate (each $10 \mathrm{~g}$ ) were added into $100 \mathrm{ml}$ water containing $0.5 \mathrm{~g}$ of SDS at $80^{\circ} \mathrm{C}$. After $10 \mathrm{~min}$ of stirring, KPS initiator was added to the solution. After $2 \mathrm{~h}$ of reaction, a milky latex solution was obtained. In the synthesis of thermoresponsive microgels [11], $N$-isopropyl acrylamide with different amounts of acrylic acid were added to water at $70^{\circ} \mathrm{C}$. The solution was stirred at a rate of $300 \mathrm{rpm}$ under a nitrogen atmosphere. A crosslinking agent, MBA, was added to the solution followed by the addition of KPS initiator. The reaction proceeded for $2 \mathrm{~h}$ and a milky latex solution was obtained. Three latex solutions with different feeding amounts of AA monomer $\left([\mathrm{AA}]_{\mathrm{o}} /[\mathrm{NIPAAm}]_{\mathrm{o}}=0,0.03,0.06\right)$ were synthesized and denoted as PN, PNAA3 and PNAA6. The conversions in all three acrylic copolymer systems were measured by a gravimetric analysis.

\subsection{Preparation of hydrogel membranes}

Hydrogel membranes with or without thermo-responsive poly(NIPAAm-coAA) microgel were prepared by a casting method. Specific amounts of glycerin, aluminum hydroxide, $\mathrm{CMC}$, poly(AA-co-SA) powder were first mixed together.
Table 1

Compositions of the doping solutions prepared to form hydrogel membranes and their sample codes

\begin{tabular}{lcccc}
\hline & \multicolumn{3}{l}{ Hydrogel membrane } & \\
\cline { 2 - 5 } & HM0 & HMPN & HMPNAA3 & HMPNAA6 \\
\hline $\begin{array}{l}\text { Poly(AA-co-SA) } \\
\text { powder (g) }\end{array}$ & 0.6 & 0.6 & 0.6 & 0.6 \\
$\begin{array}{l}\text { Poly(AA-co-EHA) } \\
\quad \text { latex }{ }^{\mathrm{a}} \text { (g) }\end{array}$ & 10 & 10 & 10 & 10 \\
$\begin{array}{l}\text { Poly(NIPAAm-co-AA) } \\
\quad \text { atex } \text { (g) }\end{array}$ & 0 & 30 (PN) & 30 (PNAA3) & 30 (PNAA6) \\
Water (g) & & & & \\
Glycerin (g) & 70 & 40 & 40 & 40 \\
Al(OH) (g) & 4.0 & 4.0 & 4.0 & 4.0 \\
CMC (g) & 0.04 & 0.04 & 0.04 & 0.04 \\
Tartaric acid (g) & 0.6 & 0.6 & 0.6 & 0.6 \\
PAA oligomer (g) & 0.04 & 0.04 & 0.04 & 0.04 \\
\hline
\end{tabular}

\footnotetext{
a Solid content $=19 \mathrm{wt} \%$.

${ }^{\mathrm{b}}$ Solid content $=2.0 \mathrm{wt} \%$.
}

The mixture was then added with tartaric acid, poly(acrylic acid) oligomer, poly(AA-co-EHA) latex solution and $70 \mathrm{~g}$ of deionized water. If poly(NIPAAmco-AA) latex solution was added, $30 \mathrm{~g}$ of water was replaced by the same weight of latex solution. After stirring for $1 \mathrm{~h}$ at room temperature, the homogeneous solution was poured into a glass Petri dish with a diameter of $12 \mathrm{~cm}$. It was then dried in a circulation oven at $50^{\circ} \mathrm{C}$ for $48 \mathrm{~h}$ to obtain a hydrogel membrane. The amounts of all ingredients added to prepare the hydrogel membranes are shown in Table 1.

\subsection{Morphology observation}

To observe the morphology of the microgels, the latex solution was diluted with deionized water. A drop of this diluted latex solution was placed on a copper grid coated with a collodion. It was then air-dried and observed by using Hitachi H-7100 transmission electron microscope (TEM). In addition, a scanning electron microscope (SEM), model S-800 from Hitachi, was used to observe the morphology of swollen hydrogel membranes. Hydrogel membranes were swollen in deionized water and then freeze-dried. To observe the cross-sectional area, cryogenic fracturing of the samples was done after freezing the samples in liquid nitrogen. All specimens were coated with a conductive layer of sputtered gold.

\subsection{LCST of poly(NIPAAm-co-AA) microgels}

The cloud point or lower critical solution temperature (LCST) of poly(NIPAAm-co-AA) microgel was measured by using an UV-vis spectrophotometer (Thermo Spectronic gamma series). Latex solution was first diluted with excess deionized water. Then, the transmittance of the solution at $450 \mathrm{~nm}$ was detected at different temperatures.

\subsection{Swelling properties}

Hydrogel membranes were swollen in deionized water at various temperatures. After $72 \mathrm{~h}$ of incubation to assure reaching equilibrium, gel samples were carefully taken out from the solution, blotted with a filter paper to remove free water from the surface, and then weighed $\left(W_{\text {wet }}\right)$. It was then freeze-dried for 1 day and weighed again $\left(W_{\text {dry }}\right)$. The swelling ratio $(\mathrm{SR}, \mathrm{g} / \mathrm{g})$ was evaluated using the equation: $\mathrm{SR}=\left(W_{\text {wet }}-W_{\text {dry }}\right) / W_{\text {dry }}$.

\subsection{Drug release behavior}

Pre-dried membranes were cut into $1 \mathrm{~cm} \times 1 \mathrm{~cm}$ square samples and then weighed $\left(W_{\mathrm{d}}\right)$. They were immersed into deionized water containing $1 \mathrm{wt} \%$ of caffeine for $2 \mathrm{~h}$. After reaching equilibrium, they were taken out and blotted 
with a filter paper to remove free water from the surface, and then weighed again $\left(W_{\mathrm{s}}\right)$. The total caffeine absorbed into membrane was then calculated as $\left(W_{\mathrm{s}}-W_{\mathrm{d}}\right) \times C$, where $C$ is the concentration of caffeine solution $(\mathrm{g} / \mathrm{g}$, caffeine/solution). The caffeine-incorporated hydrogel membranes were immersed into a 200-g deionized water at a specific temperature to observe drug release behavior with time. Several temperatures were chosen to observe the effect of thermo-responsive poly(NIPAAm-co-AA) component on the drug release behavior. The quantity of caffeine released, $M$ ( $\mathrm{g}$ caffeine), from each sample into buffer solution was measured using a UV-vis spectrophotometer (Thermo Spectronic gamma series) by detecting the characteristic absorbance of caffeine at $270 \mathrm{~nm}$. The caffeine release percentage $(\%)$ was then calculated as $M \times 100 /\left[\left(W_{\mathrm{s}}-W_{\mathrm{d}}\right) \times C\right]$.

\section{Results and discussion}

\subsection{Morphology of acrylic microgels}

In this study, emulsion polymerization was used to synthesize crosslinked poly(AA-co-SA) and poly(AA-co-EHA) copolymers, whereas poly(NIPAAm-co-AA) was synthesized by a surfactant-free emulsion polymerization. In the synthesis of poly(AA-co-SA), sodium acrylate (SA) was prepared by adding a specific amount of sodium hydroxide into the AA solution before polymerization. Since AA, SA, MBA and KPS were all water-soluble; therefore, polymerization began in water phase. The produced free radicals from the decomposition of initiator attacked monomer to produce oligomeric free radicals, which could also react with MBA crosslinking agent. Before long, as the oligomeric radicals increased in its length and became crosslinked, they changed into microgels in the water phase and adsorbed some surfactant molecules onto their surfaces. These microgels had a swollen, loosen structure with an irregular shape due to their hydrophilic property, as can be seen in Fig. 1(a). They had size in the range of $1.0-10.0 \mu \mathrm{m}$. After $3 \mathrm{~h}$ of reaction, final conversions in the synthesized poly(AA-co-SA) copolymers having different neutralization ratios $\left([\mathrm{NaOH}]_{\mathrm{o}} /[\mathrm{AA}]_{\mathrm{o}}=0.2\right.$, $0.5,0.8)$ were all above $90 \%$, and increased with increasing neutralization ratio. The conversion values were $92.5,98.8$ and near $100 \%$ for copolymer samples AS-0.2-0.1, AS-0.5-0.1 and AS-0.8-0.1\%, respectively. When a hydrophobic monomer, EHA, was used as a comonomer with AA, a more regular and round-shape microgel was observed for the produced poly(AAco-EHA) copolymer as shown in Fig. 1(b), where the size was between 150 and $400 \mathrm{~nm}$. The conversion in this system was ca. 95\%. A surfactant-free emulsion polymerization was used to synthesize thermo-responsive poly(NIPAAm-co-AA) copolymers [11]. In this reaction system, NIPAAm, AA, MBA and initiator were all water-soluble; therefore, at the initial stage of reaction, the reaction mixture was homogeneous, but it soon became heterogeneous, producing microgels as precipitates. A milky white solution thus was observed. The main reason is that crosslinked PNIPAAm chains would precipitate out from solution at high temperatures above its $\operatorname{LCST}\left(\right.$ ca. $32^{\circ} \mathrm{C}$ ). In this system, the reaction temperature was $70^{\circ} \mathrm{C}$. Fig. 2 shows uniform spherical particles were produced with $500-600 \mathrm{~nm}$ in diameter [11]. In addition, the size increased slightly with increasing amount of added AA monomer. The indistinct boundary of poly(NIPAAm-co-AA) copolymer latex was due to its hydrophilic property and high swelling degree. The final conversions of these thermo-responsive copolymers, PN, PNAA3 and PNAA6, were all nearly the same at about $95 \%$.

\subsection{LCST of poly(NIPAAm-co-AA) microgels}

In order to modulate lower critical solution temperature (LCST), poly(NIPAAm-co-AA) microgels with different compositions were synthesized. The cloud point or LCST was measured by measuring the transmittance of latex solution at $450 \mathrm{~nm}$ at different temperatures. Fig. 3 shows the optical transmittance at $450 \mathrm{~nm}$ of three poly(NIPAAm-co-AA) microgels [11]. As can be seen in Figure, LCST of pure PNIPAAm microgel (PN) was $32^{\circ} \mathrm{C}$ and it increased when a more hydrophilic
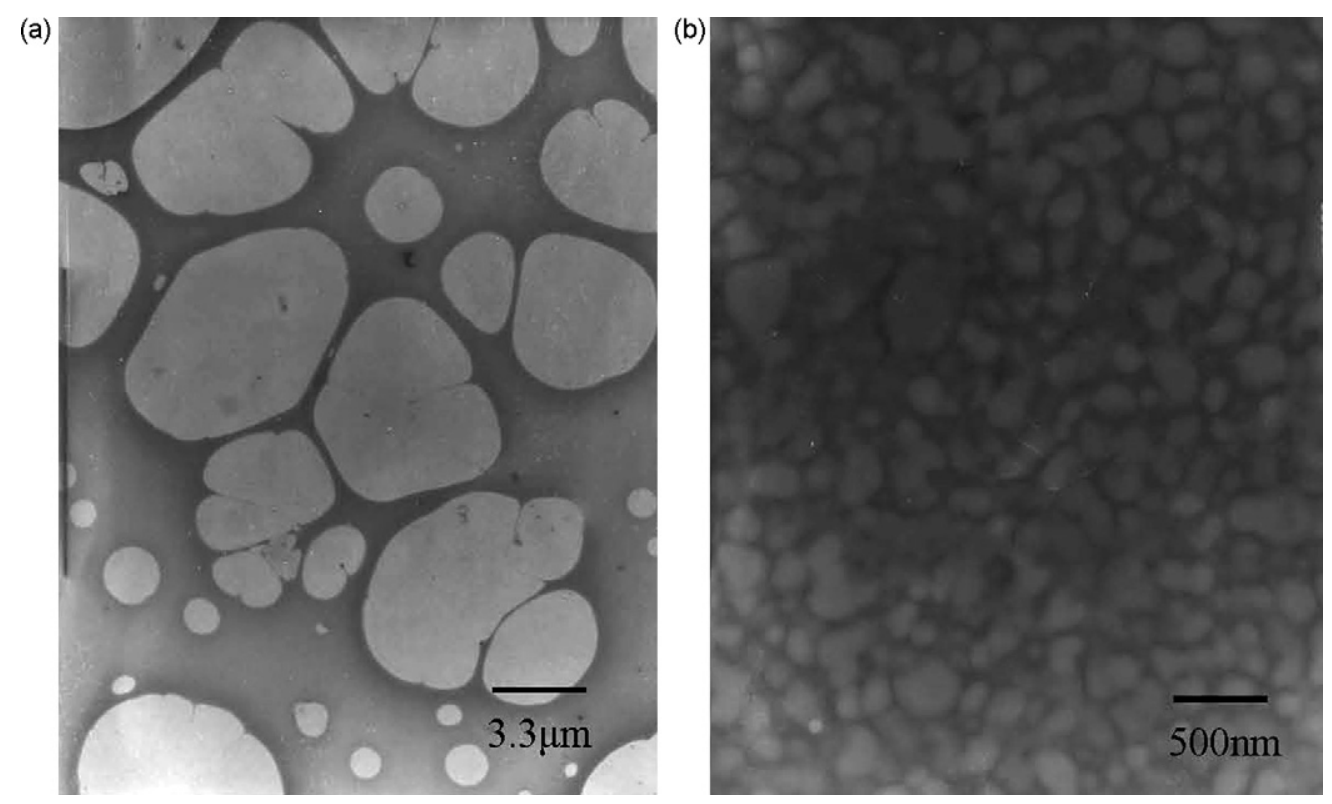

Fig. 1. TEM pictures of latex particles synthesized by emulsion polymerization. (a) poly(AA-co-SA); (b) poly(AA-co-EHA). 

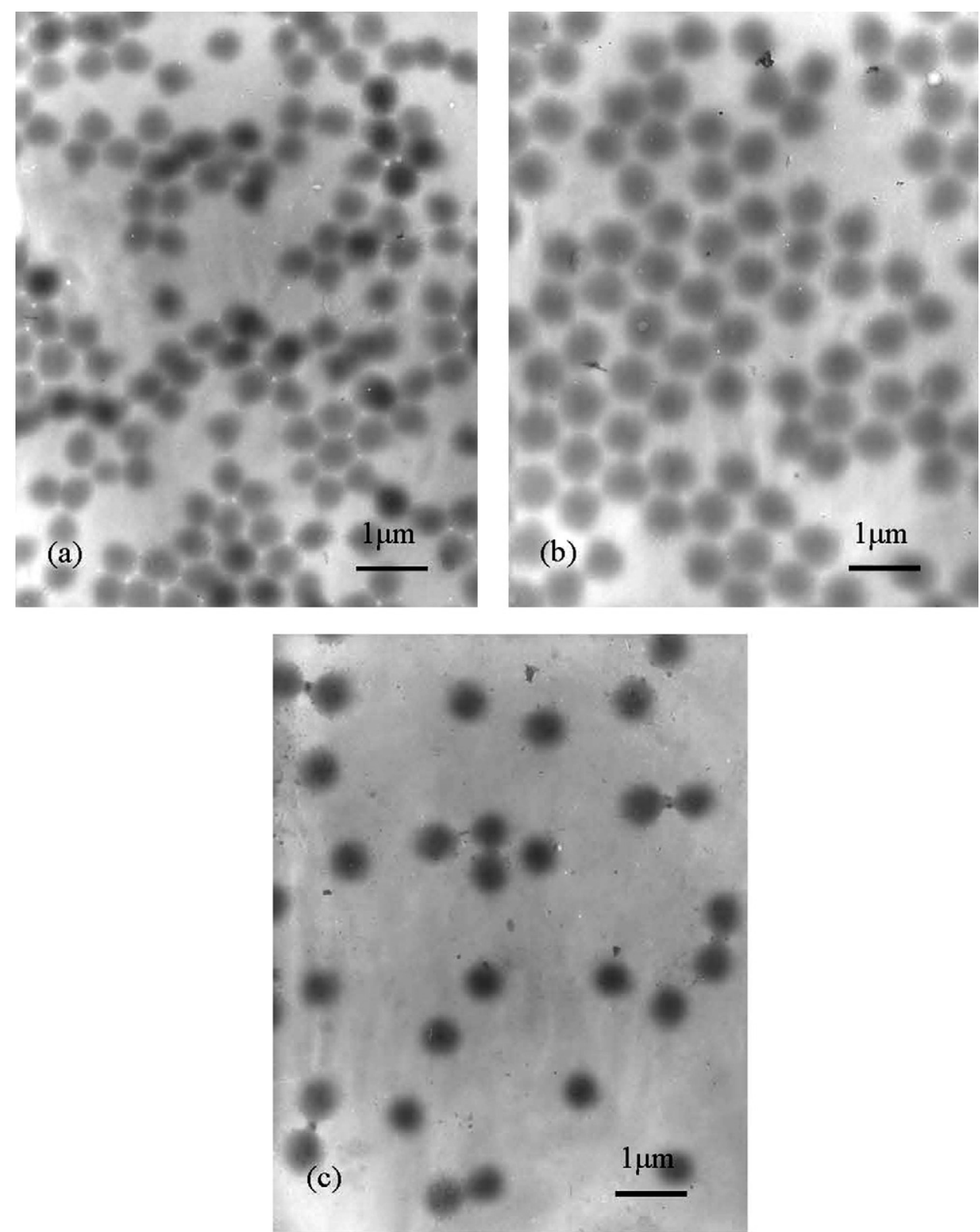

Fig. 2. TEM pictures of latex particles synthesized by surfactant-free emulsion polymerization. (a) PN, PNIPAAm homopolymer; (b) PNAA3, poly(NIPAAmco-AA) copolymer with feeding monomer ratio $[\mathrm{AA}]_{\mathrm{o}} /[\mathrm{NIPAAm}]_{\mathrm{o}}=0.03$; (c) PNAA6, poly(NIPAAm-co-AA) copolymer with feeding monomer ratio $[\mathrm{AA}]_{\mathrm{o}} /[\mathrm{NIPAAm}]_{\mathrm{o}}=0.06$.

AA monomer was incorporated. The LCST increased to 40 and $45^{\circ} \mathrm{C}$ as the molar ratio of feeding AA to NIPAAm monomer was increased to 0.03 and 0.06 (PNAA3 and PNAA6), respectively. In addition, the phase transition was also broadening due to the incorporation of AA component into polymer chain. The phenomena of increase in LCST and broadening of transition, when a hydrophilic monomer is copolymerized with NIPAAm, have been observed by various researchers [10,11-14].

\subsection{Swelling properties of hydrogel membranes}

Hydrogel membranes were prepared by the addition of the prepared copolymer microgels with several other compounds. Among them, glycerin was a water-retaining agent; carboxymethyl cellulose and poly(AA-co-SA) were the main components of hydrogel matrix; poly(AA-co-EHA) served as an adhesive component; poly(NIPAAm-co-AA) was used to give thermo-responsive property; tartaric acid and PAA oligomer were used to adjust acidity of the doping solution; aluminum hydroxide could release aluminum ion $\left(\mathrm{Al}^{3+}\right)$ which could form ionic interaction with carboxylate ion, thus giving a good membrane formability. All copolymer microgels were crosslinked, so that they could not be dissolved but only swelled in solution. Fig. 4 shows a line diagram of the formed hydrogel membrane. We first measured the swelling ratio of hydrogel membranes prepared by only addition of poly(AAco-SA) microgel. By the addition of AS-0.5-0.1\% (sample prepared from $[\mathrm{NaOH}]_{\mathrm{o}} /[\mathrm{AA}]_{\mathrm{o}}=0.5$ and $\left.\mathrm{MBA}=0.1 \%\right)$, the 


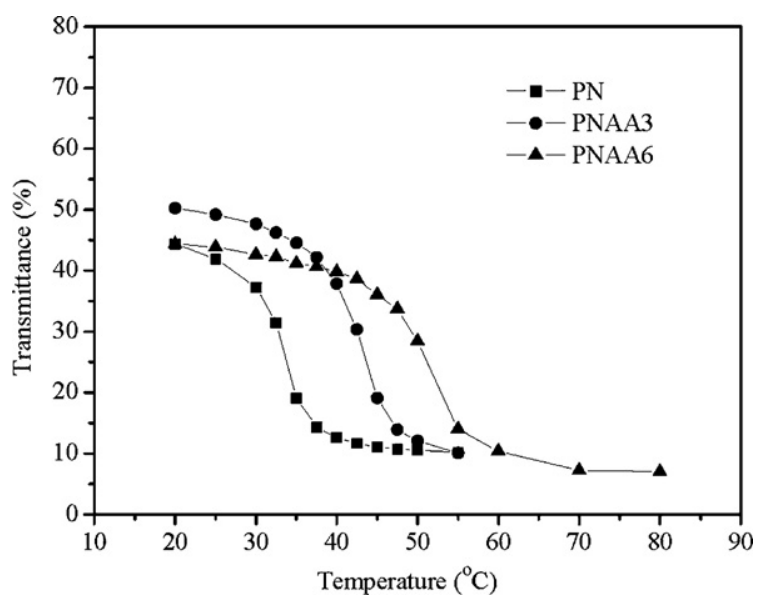

Fig. 3. Changes of optical transmittance at $450 \mathrm{~nm}$ with temperatures of three poly(NIPAAm-co-AA) latex particles, PN, PNAA3 and PNAA6.

swelling ratio of membrane at $25^{\circ} \mathrm{C}$ was about 310 and it decreased greatly to ca. 65 , if AS- $0.5-0.2 \%$ microgel, having twice amount of MBA crosslinking agent, was used instead. If a poly(AA-co-SA) copolymer with a higher degree of neutralization was used to prepare hydrogel membrane such as AS- $-0.8-0.1 \%\left([\mathrm{NaOH}]_{\mathrm{o}} /[\mathrm{AA}]_{\mathrm{o}}=0.8\right)$, membrane formability was found to be poor, though it had a higher swelling ratio. Therefore, AS- $-0.5-0.1 \%$ microgel was chosen to be incorporated into the final hydrogel membranes. Subsequently, we measured the swelling ratio of hydrogel membranes prepared by the addition of poly(AA-co-EHA) latex solution, together with $\mathrm{AS}-0.5-0.1 \%$, into the doping solution. It was found that the swelling ratio of hydrogel membrane decreased when poly(AA-co-EHA) was incorporated, and the extent of decrease was proportional to the added amount of poly(AA-co-EHA). The swelling ratio at $25^{\circ} \mathrm{C}$ was 81.4 when $5 \mathrm{~g}$ of poly(AA-coEHA) latex solution was added, and it further decreased to 50.5 when added with $10 \mathrm{~g}$. However, the adhesiveness increased with increasing the amount of poly(AA-co-EHA). An ASTM method (ASTM D3121-94) was followed to measure the initial adhesiveness. The detail was described elsewhere [15]. Briefly, the
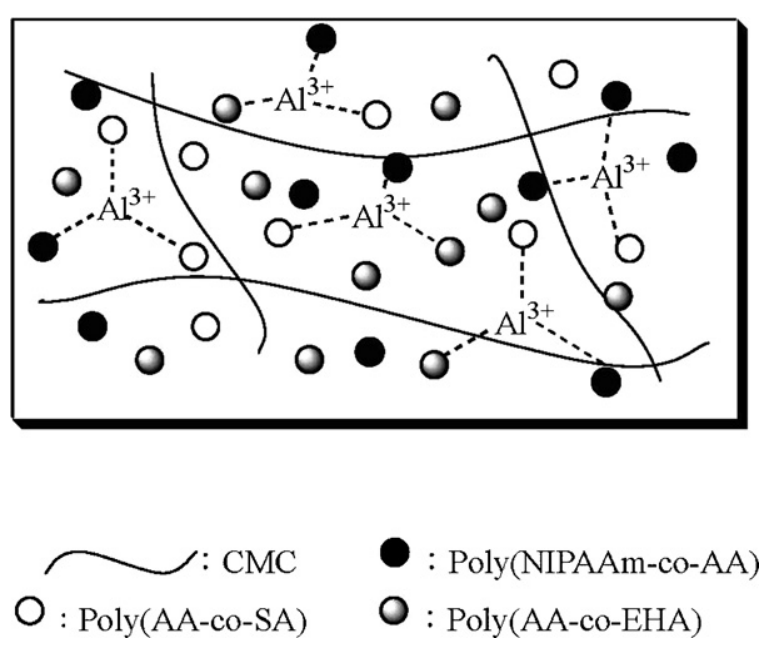

Fig. 4. A cartoon picture of the prepared hydrogel membrane. adhesiveness is inversely proportional to the traveling distance along the adhesive material of a steel ball running down from a slide. The average distance from measuring five specimens was $7.32 \mathrm{~cm}$ for membrane prepared with $5 \mathrm{~g}$ of poly(AA-co-EHA) and decreased to $4.88 \mathrm{~cm}$ for membrane with $10 \mathrm{~g}$ of poly(AAco-EHA). Therefore, the amount of poly(AA-co-EHA) latex solution was selected as $10 \mathrm{~g}$ to be added into the doping solution to prepare final hydrogel membranes.

In addition to poly(AA-co-SA) and poly(AA-co-EHA) microgels, a thermo-responsive microgel was also incorporated into final hydrogel membranes according to the recipes given in Table 1. Fig. 5 shows SEM micrographs of cross-sectional area of swollen hydrogel membranes. The controlled membrane, HM0, without the addition of PNIPAAm or its copolymer microgels, had a uniform structure with nearly the same pore size, Fig. 5(a). However, with the addition of thermo-responsive microgel, structure became non-uniform. In addition, the smaller pore clearly observed at temperatures below LCST of thermoresponsive microgel was no longer obvious when temperature was increased to above its LCST, as Fig. 5(b) and (c) were compared. Thus, it is suggested that the disappearance of smaller pores was due to the shrinkage of PNIPAAm or poly(NIPAAmco-AA) copolymer above its LCST.

The drug release behavior would be affected if there were different swelling ratios at different temperatures, especially below and above LCST of material. Fig. 6 shows the swelling curves of hydrogel membranes at different temperatures. It can be seen that without the addition of thermo-responsive microgel, swelling ratio did not depend on temperature for the controlled HM0 sample from 25 to $55^{\circ} \mathrm{C}$. The average value of swelling ratio was about 48 . This also indicates that the structure of membrane was nearly the same at this temperature range. With the addition of thermo-responsive microgel, swelling ratio was no longer the same at different temperatures; instead, a transition was observed. Two particular phenomena were found on the swelling curves. One was the broadening in transition temperature where the transition of hydrogel membrane occurred at a slightly higher temperature than the LCST of corresponding pure thermo-responsive polymer. For example, LCST of pure PNIPAAm was $32{ }^{\circ} \mathrm{C}$, where the transition of respective HMPN membrane began at $35^{\circ} \mathrm{C}$ and finished at $45^{\circ} \mathrm{C}$. This can be attributed to the existence of the other two copolymer microgels in the membrane, namely, poly(AA-co-SA) and poly(AA-coEHA), which also had acrylic acid component, thus making the membrane more hydrophilic. The other particular phenomenon was that, in contrast to the PNIPAAm polymer or its copolymer which undergoes swelling and shrinking below and above its LCST, respectively, gel membranes had a higher swelling ratio above transition temperature. For example, HMPN membrane had a swelling ratio about 32 below $35^{\circ} \mathrm{C}$; but increased nearly twice to about 60 above $35^{\circ} \mathrm{C}$. This should be explained from the consideration of the entire structure of membrane. Pure PNIPAAm or its copolymers can swell or shrink uniformly in entire sample. However, in the prepared hydrogel membranes, these thermo-responsive polymers existed as gel particles in the matrix as shown in Fig. 4. Therefore, when they underwent deswelling above LCST, the shrinkage force was not strong enough 
(a)

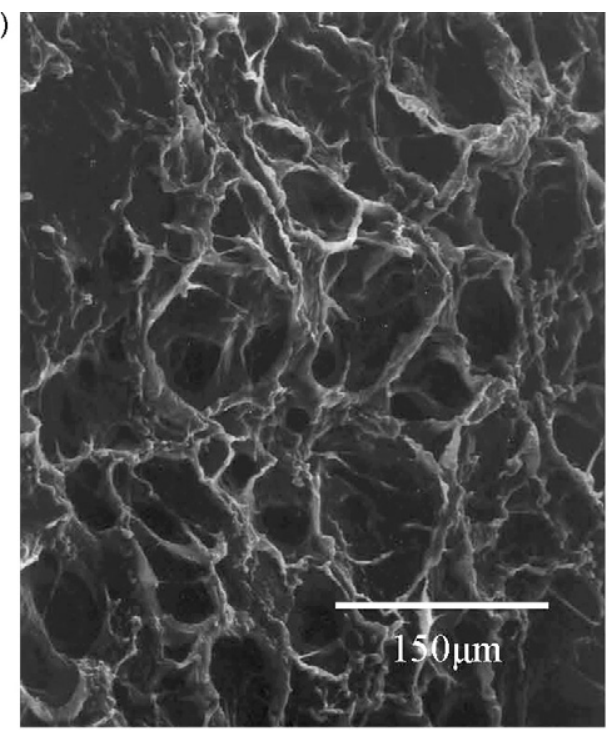

(b)

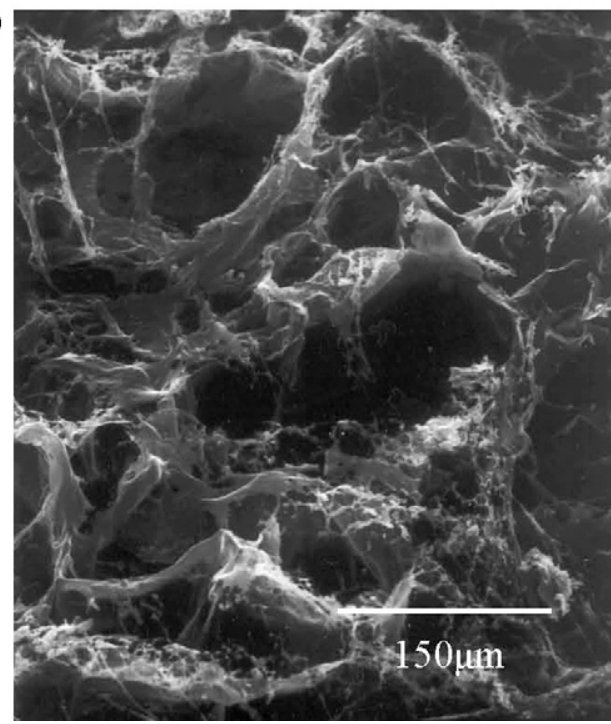

(c)

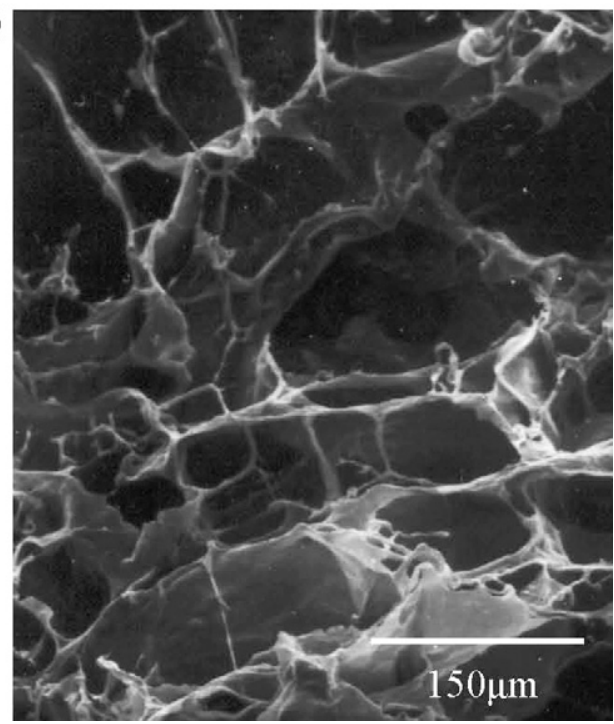

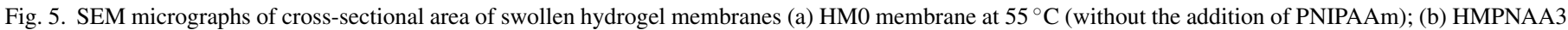
membrane at $30^{\circ} \mathrm{C}$; (c) HMPNAA 3 membrane at $50^{\circ} \mathrm{C}$.

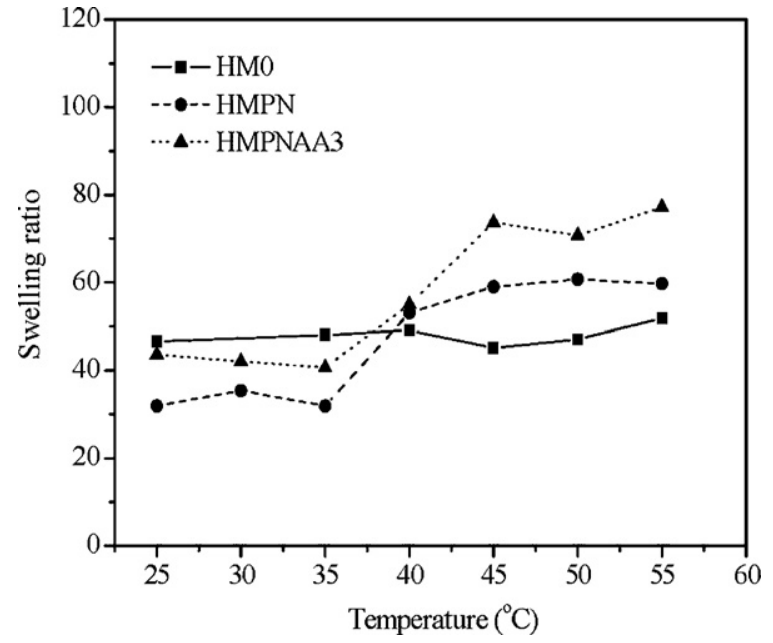

Fig. 6. Swelling curves of hydrogel membranes (HM0, HMPN, HMPNAA3 and HMPNAA6) at different temperatures. to make the entire membrane to shrink altogether. Instead, they created more space in the originally swollen membrane when the temperature was increased to above the transition temperature. Thus, the membrane could absorb more water.

\subsection{Drug release behavior}

The loading of caffeine into membrane was carried out at $25^{\circ} \mathrm{C}$, but it was released by immersion the membrane into water at different temperatures. Thus, it is important to understand the swelling behavior of various membranes at different temperatures. From previous results, it is known that the controlled membrane HMO had almost the same swelling ratio in the temperature range $25-55^{\circ} \mathrm{C}$. Fig. 7 shows the caffeine-release curves of HM0 membrane at several temperatures. It can be seen that all the curves are close to each other except the one at $25^{\circ} \mathrm{C}$. Increasing the temperature, the initial caffeine-release rate was slightly increased. This is due to the diffusivity of caffeine 


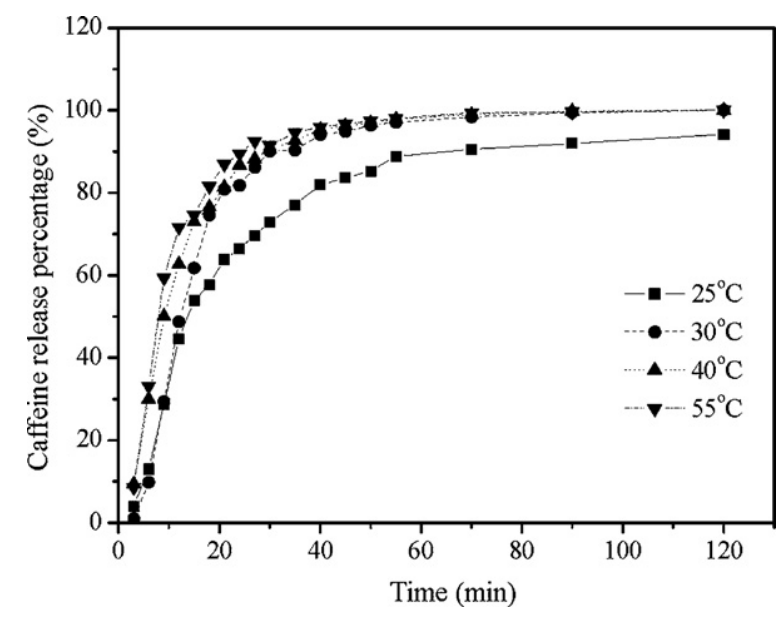

Fig. 7. Caffeine-release curves of HM0 membrane at different temperatures.

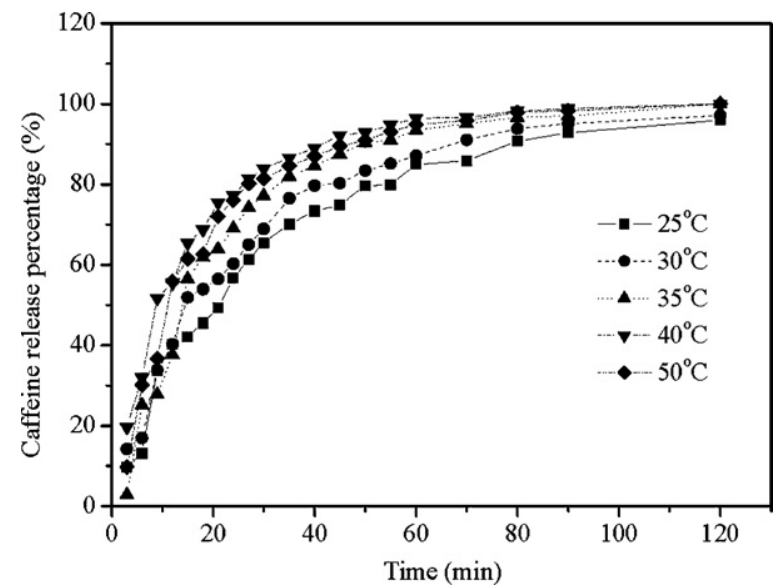

Fig. 8. Caffeine-release curves of HMPN membrane at different temperatures.

increases with temperature. Figs. 8-10 show the caffeine-release curves from various membranes incorporated with thermoresponsive gel particles. As same as in the HM0 membrane, the initial caffeine-release rate increased with increasing temperature. In the current system, it has difficulties to propose an exact caffeine-release mechanism, since the membrane structure was

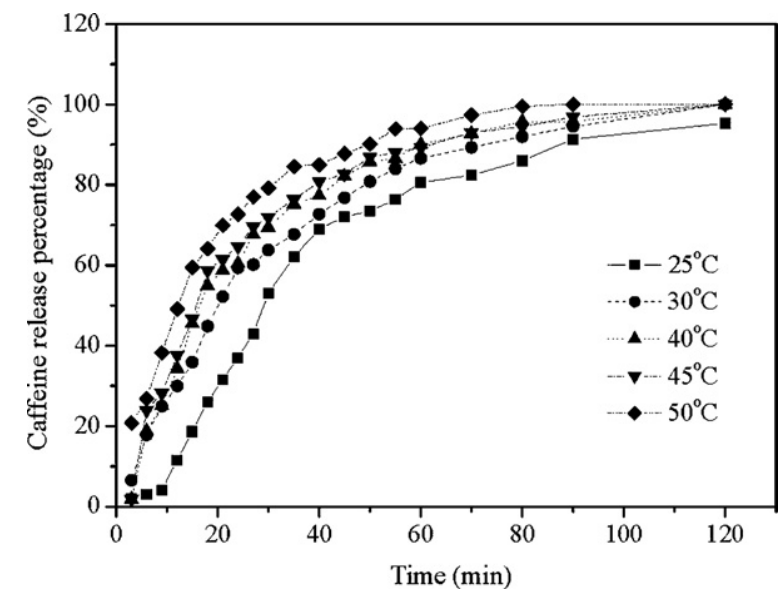

Fig. 9. Caffeine-release curves of HMPNAA3 membrane at different temperatures.

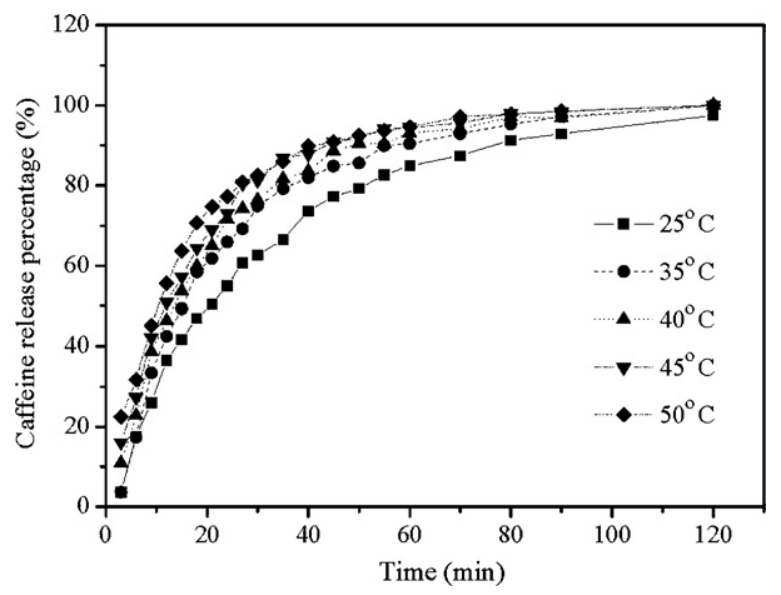

Fig. 10. Caffeine-release curves of HMPNAA6 membrane at different temperatures.

too complex as that there were different kinds of crosslinked microgels existing in the CMC matrix. These microgels having different structures and swelling ratios were associated with one another via ionic interaction through $\mathrm{Al}^{3+}$ ion. Caffeine could be absorbed into these microgel particles as well as in the CMC matrix. Different diffusion behaviors of caffeine from these microgel particles into CMC matrix would be observed, and naturally affect the subsequent diffusion of caffeine from CMC matrix into aqueous surroundings. All these would make a mathematic analysis of caffeine-release behavior very difficult. To simplify the analysis, a diffusion-controlled drug release mechanism was assumed and the initial rate constant $(k)$ for caffeine release was calculated according to the following equation by fitting the initial $60 \%$ of data.

$\frac{M_{t}}{M_{\infty}}=k t^{0.5}$

where $M_{\mathrm{t}}$ and $M_{\infty}$ are the caffeine-release amount at time $t$ and the maximum caffeine-release amount, respectively, and $k$ is the rate constant. From a linear regression, $k$ value thus can be obtained, as shown in Table 2 . The caffeine-release rate constant increased very slowly with temperature for HM0 membrane. When thermo-responsive gel particles of PNIPAAm or its copolymers were incorporated into membranes, lower rate constants were observed. At $25^{\circ} \mathrm{C}$, the caffeine-release rate constant was only $0.156 \mathrm{~min}^{-0.5}$. This indicates that the retentive ability of drug was increased by the addition of thermo-responsive

Table 2

Initial rate constant $(k)$ for the caffeine release from different hydrogel membranes

\begin{tabular}{lllll}
\hline Temperature $\left({ }^{\circ} \mathrm{C}\right)$ & \multicolumn{4}{l}{ Rate constant, $k\left(\mathrm{~min}^{-0.5}\right)$} \\
\cline { 2 - 5 } & HM0 & HMPN & HMPNAA3 & HMPNAA6 \\
\hline 25 & 0.249 & 0.156 & 0.167 & 0.166 \\
30 & 0.296 & 0.168 & 0.161 & 0.181 \\
35 & 0.302 & 0.224 & 0.185 & 0.221 \\
40 & 0.313 & 0.222 & 0.195 & 0.214 \\
45 & 0.303 & 0.206 & 0.192 & 0.210 \\
50 & 0.314 & 0.250 & 0.204 & 0.236 \\
\hline
\end{tabular}


gel particles and the drug thus could be released in a controlled rate. Furthermore, the caffeine-release rate constant was greatly increased when temperature was increased to a specific temperature, $35^{\circ} \mathrm{C}$, which was found to be close to the transition temperature of the membrane observed in swelling behavior shown in Fig. 6 . The caffeine-release rate constant was increased to $0.224 \mathrm{~min}^{-0.5}$ at $35^{\circ} \mathrm{C}$. This indicates that the swelling behavior was the main controlling factor that affected the caffeine-release behavior. At temperatures above its transition temperature, thermo-responsive microgel particles (PNIPAAm or its copolymers) underwent de-swelling and thus expelled caffeine to CMC matrix. Not only a higher swelling ratio of membrane was observed as explained previously in Fig. 6, but also a higher concentration of caffeine in the matrix. Because of these, the caffeine-release rate constant was greatly increased.

\section{Conclusions}

In this study, we have synthesized three different acrylic microgels via emulsion polymerization to be incorporated into hydrogel membranes for the application in transdermal drug delivery system. These microgels were poly(AA-co-SA), poly(AA-co-EHA) and poly(NIPAAm-co-AA), which were designed to give the membrane a higher swelling ratio, a better adhesive property and a thermo-responsive behavior, respectively. Several conclusions could be drawn from this research as follows.

1. The swelling ratio of poly(AA-co-SA) was increased by increasing the degree of neutralization, i.e., the ratio of $[\mathrm{SA}]_{\mathrm{O}} /[\mathrm{AA}]_{\mathrm{o}}$.

2. Increasing the composition of EHA in poly(AA-co-EHA) increased the adhesiveness of hydrogel membrane.

3. For pure PNIPAAm, the LCST was $32^{\circ} \mathrm{C}$. By copolymerization with a hydrophilic AA monomer to produce Poly(NIPAAm-co-AA), LCST became higher. The LCST increased to 40 and $45^{\circ} \mathrm{C}$ as the molar ratio of AA to NIPAAm monomer was increased to 0.03 and 0.06 , respectively.

4. When all three microgel particles were incorporated with other materials such as glycerin, carboxymethyl cellulose, tartaric acid, PAA oligomer and aluminum hydroxide to formulate final gel membranes, they also exhibited thermo-responsive property in swelling and caffeine-release behaviors. Below transition temperature, $35^{\circ} \mathrm{C}$, swelling ratio and initial caffeine-release rate constant were lower. Yet, when temperature was increased to above transition temperature, both values were increased greatly. For example, HMPN membrane had a swelling ratio about 32 below $35^{\circ} \mathrm{C}$; but increased nearly twice to about 60 above $35^{\circ} \mathrm{C}$. Correspondingly, the caffeine-release rate constant was increased from 0.156 to $0.224 \mathrm{~min}^{-0.5}$ as temperature was increased from 25 to $35^{\circ} \mathrm{C}$, respectively.

5. Gel particles of PNIPAAm or its copolymers underwent deswelling above LCST, creating more space for the membrane to absorb more water and in turn increasing the swelling ratio. Also, they simultaneously expelled caffeine to the highly swollen CMC matrix, thus increasing the caffeine-release rate.

\section{References}

[1] Y. Hirokawa, T. Tanaka, Volume phase transition in a nonionic gel, J. Chem. Phys. 81 (12) (1984) 6379-6380.

[2] A.S. Hoffman, Applications of thermally reversible polymers and hydrogels in therapeutics and diagnostics, J. Control. Rel. 6 (1) (1987) 297-305.

[3] T.-M. Don, H.-R. Chen, Synthesis and characterization of AB-crosslinked graft copolymers based on maleilated chitosan and $\mathrm{N}$-isopropylacrylamide, Carbohydr. Polym. 61 (3) (2005) 334-347.

[4] T. Tanaka, Phase transitions in gels and a single polymer, Polymer 20 (11) (1979) 1404-1412.

[5] Q. Yan, A.S. Hoffman, Synthesis of macroporous hydrogels with rapid swelling and deswelling properties for delivery of macromolecules, Polymer 36 (4) (1995) 887-889.

[6] A.R. Khare, N.A. Peppas, Swelling/deswelling of anionic copolymer gels, Biomaterials 16 (7) (1995) 559-567.

[7] M. Ilavsky, Phase transition in swollen gels. 2. Effect of charge concentration on the collapse and mechanical behavior of polyacrylamide networks, Macromolecules 15 (3) (1982) 782-788.

[8] C.K. Chee, S. Rimmer, I. Soutar, L. Swanson, Fluorescence investigations of the thermally induced conformational transition of $\operatorname{poly}(N$-isopropylacrylamide), Polymer 42 (12) (2001) 5079-5087.

[9] Y. Tanaka, Y. Kagami, A. Matsuda, Y. Osada, Thermoreversible transition of tensile modulus of hydrogel with ordered aggregates, Macromolecules 28 (7) (1995) 2574-2576.

[10] T. Aoki, M. Kawashima, H. Katono, K. Sanui, N. Ogata, T. Okano, Y. Sakurai, Temperature-responsive interpenetrating polymer networks constructed with poly(acrylic acid) and poly( $N, N$-dimethylacrylamide), Macromolecules 27 (4) (1994) 947-952.

[11] C.L. Lin, W.Y. Chiu, C.F. Lee, Preparation, morphology, and thermoresponsive properties of poly ( $N$-isopropylacrylamide)-based copolymer microgels, J. Polym. Sci. Part A-Polym. Chem. 44 (1) (2006) 356-370.

[12] M.K. Yoo, Y.K. Sung, Y.M. Lee, C.S. Cho, Effect of polyelectrolyte on the lower critical solution temperature of poly ( $N$-isopropyl acrylamide) in the poly(NIPAAm-co-acrylic acid) hydrogel, Polymer 41 (15) (2000) 5713-5719.

[13] J. Zhang, N.A. Peppas, Morphology of poly(methacrylic acid)/poly( $N$ isopropyl acrylamide) interpenetrating polymeric networks, J. Biomater. Sci. Polym. Ed. 13 (5) (2002) 511-525.

[14] C. Peniche, W. Arguelles-Monal, N. Davidenko, R. Sastre, A. Gallardo, J. San Roman, Self-curing membranes of chitosan/PAA IPNs obtained by radical polymerization: preparation, characterization and interpolymer complexation, Biomaterials 20 (20) (1999) 1869-1878.

[15] M.-L. Huang, Synthesis of thermo-sensitive acrylate hydrogels and its controlled drug release study, MS Thesis, National Taiwan University, Taipei, Taiwan, 2005. 